\title{
The Glowing Bacteria - The Living Micro L.E.Ds
}

\section{Girish B Mahajan ${ }^{1 *}$ and Dipali Rahul Phatak ${ }^{2}$}

${ }^{1}$ HiMedia Laboratories Pvt. Ltd., Mumbai, India

${ }^{2} J o g e s h w a r i$ Education Society, Mumbai, India

*Corresponding Author: Girish B Mahajan, HiMedia Laboratories Pvt. Ltd., Mumbai, India.

Received: September 04, 2019; Published: October 09, 2019

DOI: $10.31080 /$ ASMI.2019.02.0391

\section{Abstract}

Bio-luminous bacteria (The light emitting bacteria) are the most widely distributed light-emitting organisms with the majority existing in marine-water and the remaining residing in the terrestrial or freshwater environment. While most species of luminescent bacteria are capable of living free, the majority are found in nature associated in symbiosis with host organisms such fishes and shrimps. There are three major genera, into which most Bio-luminous bacteria are classified; Photobacterium, Vibrio, and Xenorhabdus. It will be interesting to know some unique features of these and potential applications of these light emitters.

Keywords: Bio-luminous; Bacteria

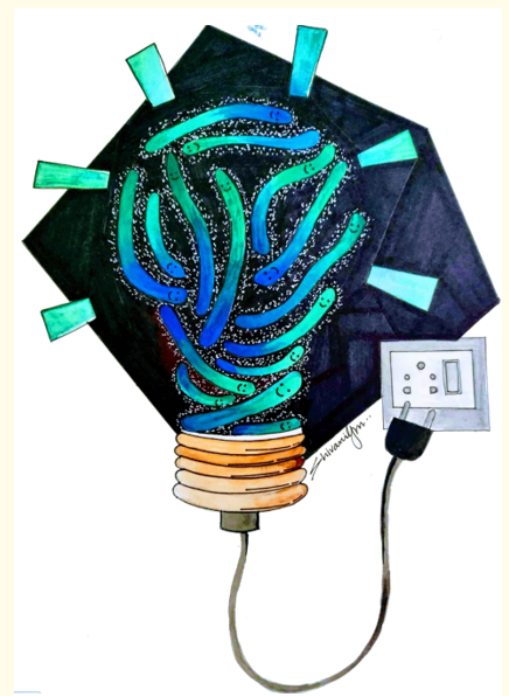

Figure 1
What are glowing bacteria?

The faint strange bluish-green glow of fireflies is a summer night fascination for all of us. Certain regions in India are famous for fireflies' habitats. Enthusiastic travellers and nature lovers arrange special night trails to experience the glow in nature. The fireflies and their light have been a subject to the heart of many poets, writers, film directors, photographers, and nature lovers. From ancient days several application specialists have marketed fireflies well ahead in creative ways. All these nature innovation devotees would be stunned to learn that there are 100,000 times tinier lives than fireflies which can glow themselves irrespective of season, time of the day or geographic habitats. Yes!! Your guess is right. We are talking about the bacteria of the dimensions of about 1-8 micrometres $(\mu \mathrm{m})$ length $\times 1 \mu \mathrm{m}$ width and they glow. The group of bacteria titled 'Bioluminescent Bacteria' (BLB). They can be compared as micro-LEDs. 


\section{Where are these live Micro-LEDs found?}

These micro-LEDs are predominantly present in marine water \& sediments, the surface of fish and in the gut of marine animals, etc. If one looks through the powerful telescope towards the darkness of sky on a pitch-dark night, a beautiful spread-out of galaxies and stars can be seen as tiny bluish-greenish spots of various sizes. This view makes us understand how the enormously huge universe is! In an analogous way if we focus our microscope on lighting wave edges of some oceans (Koh Rong beach, Manialtepec Lagoon, Many islands of Mexico such as Holbox-Quintana Roo, Chacahua-Oaxaca, etc) we can view exactly similar picture, displaying bluish-green tiny bacterial spots in the dark water. Mexico is the keeper of some magical beaches where tourists can delight in the phenomenon of bioluminescence, that is, the production and emission of light by thousands of living organisms. This view would make us feel how ignorant are we about the sizes of the light sources in nature.

\section{About the light of these living Micro-LEDs}

The BLBs in spite of primitive creatures on the earth like other bacteria they have evolved special ability to radiate the light of particular colors. Bacterial bioluminescence is the "cold light" produced and emitted by bacterial cells, including both wild-types luminescent and genetically engineered bacteria. The color of this radiated light is bluish green, aqua-blue or green. The bioluminescence is measured by very advanced instruments such as photomultiplier tube and charge-coupled device (CCD) camera. About 35,500 fireflies are equivalent to the 100 -watt bulb with respect to visible light emissions. $\sim 3.5 \times 1012$ bioluminescent bacteria have the power to emit similar visible light intensity.

\section{History and BLB's classification}

Records of BLBs existed for thousands of years. They appear in the folklore of many regions, including Scandinavia and the Indian subcontinent. Both Aristotle and Charles Darwin have described the phenomenon of the oceans glowing. Luciferase is an enzyme responsible for emitting light. It was first purified by McElroy and Green from the USA in 1955. Scientifically these BLBs belong to the class Gammaproteo bacteria. They are further classified into three groups viz. Vibrio, Photobacterium, and Xenorhabdus. Bacteria within the group Vibrio and Photobacterium usually exist in the marine environment and Xenorhabdus belong to the terrestrial environment. It is very interesting to know how these tiny creatures can produce light from their primitive metabolism.
What makes these bacteria emit light?

Bioluminescence is the phenomenon that consists of visible light radiation from the results of biochemical and enzymatic activity of the living organism. A set of genes called 'lux operon' is present in BLBs and it helps to produce the luciferase enzymes. The enzyme acts on a long-chain aliphatic aldehyde (called Luciferin) and reduced flavin mononucleotide (FMNH2). This mechanism needs oxygen. In this process, the excess energy is liberated as the light of blue-green color. This is one of the beautiful processes happening inside the bacterial cell liberating visible light.

What is the significance of the light for the microbe and environment?

The exact use of this glowing to the microbe is still under discovery. Nevertheless, a couple of hypotheses are put to explain it. Example, it can function as an alternate pathway for electron flow under low oxygen concentration for respiration, which can be advantageous when no food is available. In this process, light emission is a side product of metabolism. Another hypothesis is bacterial luciferase contributes to the resistance of oxidative stress. It also believed that bacterial bioluminescence attracts predators that will assist in their dispersion in the environment.

\section{BLBs and their relation with other life}

BLBs are found as a symbiotic partner with many invertebrates and other animals in oceans. The Hawaiian squid and the marine gram-negative BLB, Aliivibrio fischeri exhibit a mutualistic relationship. Bioluminescence produced by $A$. fischeri helps to attract prey to the squid host, which in turn provides nutrient-rich tissues and a protected environment for $A$. fischeri. Once the BLBs colonize, the specialized organs of the squid undergo developmental changes and a win-win relationship becomes established with BLBs. The lovely blue-green sheen of the bacteria is also used by fishes and squids in sex-specific signaling, predator avoidance, and locating or attracting prey, etc (Figure 2).

\section{Bacteria control their light by cell-to-cell talking}

Glow in bacteria can be regulated through a phenomenon known as quorum sensing, which is a form of cell-to-cell communication that alters gene expression in response to cell numbers. A special hormone called pheromone produced constitutively by BLBs and it serves as a signaling molecule. When the concentration of this pheromone reaches a threshold at a particular higher number of BLBs, it induces the expression of luciferase and oth- 
er enzymes involved in bioluminescence. It means bacteria start glowing when particular cell density is achieved in a highly oxygen reach environment. A sufficiently high cell population ensures that the bioluminescence produced by the cells will be visible in the environment. Perhaps light radiation is a way to gauze population in these micro LEDs.

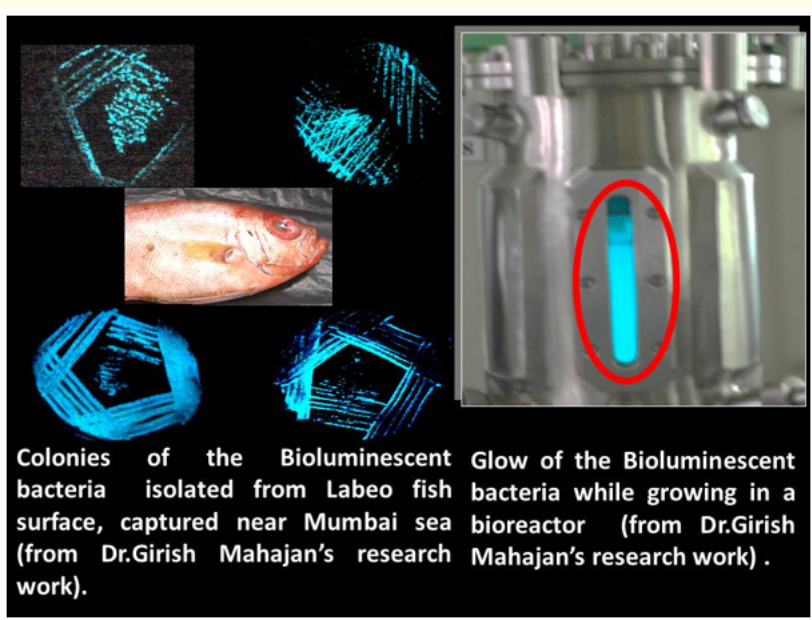

Figure 2

\section{Micro-LEDs and human}

For a human, the charming, eye-pleasing and enchanting view of blue flames of ocean waves on a dark night due to BLBs is a treat for heart and mind. Moreover, the BLBs are non-pathogenic and non-toxic. These natural glowing entities in nature can be used as decoration resource, without the use of electricity or fossil fuel. Its light is cooler than moonlight. These Micro-LEDs multiply exponentially when the right environment is provided. Its containers which are transparent can be shaped the way we like. In fact, a start up company called 'Glowee' has come up to make streets pretty bright while also cutting down on electricity use. We can think of thinnest natural tube light, bulbs, wires to any finest shapes which can glow with these tiny friends. Luminescent bacteria have the potential to use as accurate indicators of marine water quality. More the pollution lesser is the percentage of glow from that sea water. Fecal contamination reduces the glow of seawater drastically. The glow of BLBs is also correlated with the concentration of glucose. So these micro-LEDs could be good resources for glucose diagnostic kits. Isolation and characterization of glowing bacteria from such marine or other resources is an easy and sat- isfying project for microbiologists. These BLBs are a great source of the high value luciferase enzyme. Certain Photobacteria derived Luciferin-luciferase assay is used for growth measurement of other bacteria. The BLBs are used in several in-vitro toxicological studies. Immobilized BLBs are used as biosensors.

The blue-green heavenly glow by these BLBs can be explored more imaginatively and creatively for their new applications. They have the potential of creating a new era of natural optical \& photo systems and equipment's.

\section{Acknowledgment}

The authors are very thankful to their respective affiliation institutes for encouraging publishing of such awareness articles for wide readers of the journal. Authors of the article hereby gratefully acknowledge the Editor and senior management of the monthly periodical titled 'Abhineet' published by 'Asha Foundation (https:// indiaasha.org/)' for approving the copyrights for the publication of the article, which was published in 'Abhineet' in the joint issue of July-August-2019. The authors are also thankful to Shivani G. Mahajan for drawing, painting and providing the apt and creative painting for this article.

\section{Volume 2 Issue 11 November 2019 \\ (C) All rights are reserved by Girish B Mahajan and Dipali Rahul Phatak.}

